\title{
The Obstetric and Neonatal Implications of a Low Value on the 50-g Glucose Screening Test
}

\author{
Kimberly K. Ma, MD¹, Lisa Mele, ScM², Mark B. Landon, MD³ ${ }^{3}$ Catherine Y. Spong, MD $^{4}$, \\ Susan M. Ramin, MD ${ }^{5}$, Brian Casey, MD $^{6}$, Ronald J. Wapner, MD ${ }^{7}$, Michael W. Varner, MD $^{8}$, \\ Dwight J. Rouse, MD ${ }^{9}$, John M. Thorp Jr., MD ${ }^{10}$, Anthony Sciscione, DO ${ }^{11}$, Patrick \\ Catalano, MD ${ }^{12}$, Margaret Harper, MD, MSc ${ }^{13}$, George Saade, MD ${ }^{14}$, Steve N. Caritis, MD ${ }^{15}$, \\ Yoram Sorokin, MD ${ }^{16}$, and Alan M. Peaceman, MD $^{17}$ for the Eunice Kennedy Shriver \\ National Institute of Child Health and Human Development Maternal-Fetal Medicine Units \\ Network
}

${ }^{1}$ Department of Obstetrics and Gynecology of the Oregon Health and Science University, Portland, Oregon ${ }^{2}$ The George Washington University Biostatistics Center, Rockville, Maryland ${ }^{3}$ The Ohio State University, Columbus, Ohio ${ }^{4}$ The Eunice Kennedy Shriver National Institute of Child Health and Human Development, Bethesda, Maryland ${ }^{5}$ The University of Texas Health Science Center at Houston, Houston, Texas ${ }^{6}$ University of Texas Southwestern Medical Center, Dallas, Texas ${ }^{7}$ Columbia University, New York, New York ${ }^{8}$ University of Utah, Salt Lake City, Utah ${ }^{9}$ University of Alabama at Birmingham, Birmingham, Alabama ${ }^{10}$ University of North Carolina at Chapel Hill, Chapel Hill, North Carolina ${ }^{11}$ Drexel University, Philadelphia, Pennsylvania ${ }^{12}$ Case Western Reserve University-MetroHealth Medical Center, Cleveland, Ohio ${ }^{13}$ Wake Forest University Health Sciences, Winston-Salem, North Carolina ${ }^{14}$ University of Texas Medical Branch, Galveston, Texas ${ }^{15}$ University of Pittsburgh, Pittsburgh, Pennsylvania ${ }^{16}$ Wayne State University, Detroit, Michigan ${ }^{17}$ Northwestern University, Chicago, Illinois

\section{Abstract}

Objective-To assess the relationship between a low 50-g 1-hour glucose loading test (GLT) and maternal and neonatal outcomes in women without diabetes.

Study Design-This was a secondary analysis of a multicenter observational cohort from a randomized trial of treatment for mild gestational diabetes. Maternal and neonatal outcomes were compared between women with GLT values $<90 \mathrm{mg} / \mathrm{dL}$ and those with results 90 to $119 \mathrm{mg} / \mathrm{dL}$.

Results-Of 436 enrolled women, 297 (68.1\%) had a GLT result of 90 to $119 \mathrm{mg} / \mathrm{dL}$ and 139 (31.9\%) had a result of $<90 \mathrm{mg} / \mathrm{dL}$. There was a lower incidence of neonatal hypoglycemia in those with a GLT $<90 \mathrm{mg} / \mathrm{dL}(5.7 \%$ versus $16.5 \%, p=0.006)$. Other outcomes were not associated with test results.

Copyright ( 2013 by Thieme Medical Publishers, Inc.,

Address for correspondence Kimberly K. Ma, MD, 1959 NE Pacific Street, Box 356460, Seattle, WA 98195, kkma@uw.edu. Presented at the 58th Annual Meeting, Society for Gynecologic Investigation; Miami, Florida; March 16-19, 2011. 
Conclusion-A GLT result $<90 \mathrm{mg} / \mathrm{dL}$ compared with 90 to $119 \mathrm{mg} / \mathrm{dL}$ is associated with a lower risk of neonatal hypoglycemia, but no other significant findings.

\section{Keywords}

low glucose screening test; neonatal hypoglycemia

Gestational diabetes mellitus (GDM) affects 2 to $5 \%$ of pregnancies depending on the population; some groups have an incidence as high as $14 \% .^{1,2}$ The American College of Obstetricians and Gynecologists states all pregnant women should be screened for GDM either by history, clinical risk factors, or laboratory screening tests. ${ }^{3}$ Several recent large studies have evaluated the effects of maternal hyperglycemia and pregnancy outcomes. These trials demonstrated treatment of even mild GDM reduced the risks of fetal macrosomia, large-for-gestational-age infants, shoulder dystocia, cesarean delivery, and hypertensive disorders. ${ }^{4,5}$

There have been fewer research studies examining the impact of maternal hypoglycemia on pregnancy outcomes, but this could potentially impact fetal growth. Several placental hormones including growth hormone, corticotropin-releasing hormone, chorionic somatomammotropin, and progesterone contribute to insulin resistance in pregnancy. Cytokines and tumor necrosis factor- $\alpha$ also contribute to insulin resistance in pregnancy. ${ }^{6}$ Metabolic changes in pregnancy reflect a patient's pregravid metabolic status, and therefore the glucose loading test (GLT) may give insight on metabolic profiles outside of pregnancy. ${ }^{7}$

Altered glucose production and insulin resistance have been studied in hyperglycemic pregnancy states and their relationship to maternal and neonatal outcomes, but less is known about the converse state. Table 1 shows a summary of previous work examining hypoglycemia and the outcomes. Early studies stratified study and control groups by those with intrauterine growth restriction or low-birth-weight infants and then studied their glucose test results. ${ }^{8-10}$ More recent studies have looked at outcomes of those with mild hypoglycemia, but both studies included those with elevated values on the glucose test in their control group. ${ }^{11,12}$ However, women with even a single abnormal value on the glucose tolerance test are at risk for macrosomia, neonatal morbidity, cesarean delivery, and preeclampsia, which could complicate the comparison between a low GLT value and other values. ${ }^{13,14}$ The objective of this study was to evaluate the relationship between a low value (less than $90 \mathrm{mg} / \mathrm{dL}$ ) on the maternal GLT and maternal and neonatal morbidity outcomes compared with women with a GLT value 90 to $119 \mathrm{mg} / \mathrm{dL}$.

\section{Materials and Methods}

\section{Design}

This was a secondary analysis of a Eunice Kennedy Shriver National Institute of Child Health and Human Development Maternal-Fetal Medicine Units Network multicenter observational cohort assembled alongside a randomized controlled trial of treatment for mild gestational diabetes. ${ }^{4}$ Patients were recruited from October 2002 to mid-November 2007. 
This cohort included all women between 24 weeks 0 days and 30 weeks 6 days of gestation with a serum value less than $120 \mathrm{mg} / \mathrm{dL} 1$ hour after a 50-g GLT. Ultrasonography was performed in all subjects prior to the oral glucose screening test to confirm gestational age.

In the original study, four populations were studied. The first population consisted of women with a diagnosis of mild GDM who were randomized to treatment of GDM. The second population also had a diagnosis of mild GDM, but instead was randomized to routine prenatal care. The third population consisted of women who had a glucose value between 135 and $200 \mathrm{mg} / \mathrm{dL} 1$ hour after a 50-g GLT but had a normal subsequent 3-hour 100-g glucose tolerance test. These women were matched with the GDM randomized women, with respect to race/ethnicity and body mass index (BMI) dichotomized as less than 27 or 27 and more. The fourth population was an observational cohort that consisted of women with a glucose value less than $120 \mathrm{mg} / \mathrm{dL}$ after a 50-g GLT and thus unlikely to have GDM. These women were also matched to the randomized group by race/ethnicity and BMI category, continued routine prenatal care, and did not receive any treatment for GDM. This last population was the cohort studied in the current analysis. Women with values between 120 and $135 \mathrm{mg} / \mathrm{dL}$ were not recruited into the original study to limit false-negatives for GDM.

Exclusion criteria were preexisting diabetes, an abnormal result on a glucose screening test prior to 24 weeks of gestation or prior GDM; a history of stillbirth, multifetal gestation, asthma, chronic hypertension, or corticosteroid use; a known fetal anomaly; or if imminent or preterm delivery was likely because of maternal disease or fetal conditions.

The records of all enrolled women and their infants were reviewed at the time of their discharge from the hospital, and information regarding antepartum, intrapartum, and postdelivery complications was recorded.

\section{Data}

Maternal demographic characteristics, including maternal age, race, tobacco use, alcohol use, and obesity were examined. Obesity was defined as a prepregnancy BMI greater than or equal to $30 \mathrm{~kg} / \mathrm{m}^{2}$. Maternal outcomes such as weight gain from the time of study enrollment were recorded. Labor and delivery characteristics such as type of labor (induced, augmentation, or spontaneous) and mode of delivery and maternal morbidity such as presence of preeclampsia, gestational hypertension, or abruption were analyzed. All cases of hypertensive disorders underwent masked central review by two of the authors to ensure that the diagnoses were accurate.

Neonatal blood for glucose determination was collected for all neonates, if possible, within 2 hours of birth and before first feeding. Hypoglycemia was defined as a glucose value less than $35 \mathrm{mg} / \mathrm{dL} .{ }^{15}$ Small for gestational age was defined as birth weight less than the 10th percentile of a U.S. reference population. Large for gestational age was defined as birth weight above the 90th percentile of a U.S. reference population. ${ }^{16}$ Birth weight percentiles were generated using a customized growth standard. ${ }^{17}$ Serum bilirubin was determined between 16 and 36 hours after birth for all neonates, if possible. A bilirubin value greater than the 95 th percentile was considered to be an elevated level. ${ }^{18}$ Data were collected on 
gestational age at birth, birth weight, birth length, admission to the neonatal intensive care unit (NICU), and various neonatal morbidities.

\section{Statistical Analysis}

Maternal and neonatal outcomes were compared between women with values in the lowest tertile $(<90 \mathrm{mg} / \mathrm{dL})$ and those with higher screening results $(90$ to $119 \mathrm{mg} / \mathrm{dL})$. The threshold of $90 \mathrm{mg} / \mathrm{dL}$ was chosen as there has been previous work suggesting women with GLT values less than $90 \mathrm{mg} / \mathrm{dL}$ were at risk for fetal growth restriction and neonatal intensive care admissions. ${ }^{11,12}$ Additionally, subgroup analyses were conducted by 10 $\mathrm{mg} / \mathrm{dL}$ increments.

Obstetric and neonatal outcomes were compared between groups. Categorical variables were analyzed using the chi-square test or Fisher exact test. Continuous variables were analyzed using the Wilcoxon rank sum test or the Kruskal-Wallis test. The Cochran-Armitage test was used to test for trends between GLT level in 10-mg increments and neonatal hypoglycemia. ${ }^{19}$ Receiver operating characteristic (ROC) curves were generated to look at the ability of the GLT to predict outcomes.

A result was considered statistically significant if the $p$ value was less than 0.05 and no adjustments were made for multiple comparisons. Analyses were performed with SAS statistical software (SAS Institute Inc, Cary, NC).

All women who participated in the study provided written informed consent. The primary study was approved by the human subjects committee at each participating center. Institutional Review Board approval was received for this secondary analysis prior to study initiation.

\section{Results}

Four hundred thirty-six women were enrolled into the cohort. One hundred thirty-nine women (31.9\%) had a GLT result < $90 \mathrm{mg} / \mathrm{dL}$ and 297 (68.1\%) had a test result of 90 to 119 $\mathrm{mg} / \mathrm{dL}$. There were no significant differences in the demographic characteristics between the two groups except GLT value (Table 2, $p=0.0001$ ).

There were no significant differences in maternal outcomes between the groups (Table 3 ). No significant difference in the incidence of gestational hypertension/preeclampsia was seen in those with a GLT $<90 \mathrm{mg} / \mathrm{dL}$ compared with those who had a GLT $<90 \mathrm{mg} / \mathrm{dL}$ ( $p=$ $0.16)$.

The neonatal outcomes are summarized in Table 4. Although not significant, there was a trend toward increased small-for-gestational-age infants $(p=0.10)$ and NICU admissions $(p$ $=0.11$ ) in the group with a GLT $<90 \mathrm{mg} / \mathrm{dL}$. Examination of the mean birth weight did not show a difference between the two groups $(p=0.94)$. There was a significantly lower incidence of neonatal hypoglycemia (glucose $<35 \mathrm{mg} / \mathrm{dL}$ within 2 hours of birth) in those with a GLT $<90 \mathrm{mg} / \mathrm{dL}(5.7 \%$ versus $16.5 \%, p=0.006)$. Examination by $10-\mathrm{mg}$ increments showed a trend of increasing neonatal hypoglycemia with higher GLT value ( $p=0.011$, test for trend, Table 5). There were no differences in neonatal hyperbilirubinemia between the 
two groups: GLT $<90 \mathrm{mg} / \mathrm{dL}$ or GLT $\geq 90 \mathrm{mg} / \mathrm{dL}$. There were also no differences in hyperbilirubinemia when the cohort was examined in 10-mg increments (Table 6). An ROC curve was generated for further sensitivity analysis to compare whether the GLT could predict neonatal hypoglycemia. The area under the curve was $0.63(0.54,0.72)$, indicating GLT was a modest predictor of neonatal hypoglycemia.

\section{Discussion}

Although our study did not find a correlation between a low value on maternal GLT and maternal morbidity, neonatal outcomes were affected. Most significant is the difference between the rates of neonatal hypoglycemia in these groups despite similar rates of largefor-gestational-age infants in both groups. Although we found a trend toward small-forgestational-age infants in women with a GLT $<90 \mathrm{mg} / \mathrm{dL}$ compared with those with a GLT 90 to $119 \mathrm{mg} / \mathrm{dL}$, this was not statistically significant $(p=0.10)$. This trend corroborates previous research indicating neonatal morbidity with maternal hypoglycemia on GLT. ${ }^{8,12}$ In animal studies, maternal hypoglycemia during pregnancy has been associated with a decrease in fetal glucose, an increase in protein breakdown, and an increase in oxidative metabolism. These factors contribute to slower rates of fetal growth and decreased fetal insulin. $^{20}$

Previous work suggested mildly low GLT values were associated with NICU admissions. However, the etiology of increased NICU admissions was unclear, although it was hypothesized it could be due to an increased rate of neonatal hypoglycemia. ${ }^{12}$ Our study did not confirm an increased risk for NICU admissions with a lower GLT value. However, the previous work included women with an abnormal GLT but normal 3-hour $100 \mathrm{~g}$ glucose tolerance test, which is not reflective of the population in this study.

The rate of neonatal hypoglycemia is estimated to be $10 \%$ in normal term infants. ${ }^{21}$ This is consistent with the overall rate of neonatal hypoglycemia in this cohort (10.1\%). It is plausible with a lower GLT value, relative fetal and neonatal hyperinsulinemia is reduced, therefore making neonatal hypoglycemia less common. Divided into $10-\mathrm{mg} / \mathrm{dL}$ increments, there was a trend toward increasing rates of neonatal hypoglycemia with increasing GLT value.

These results are similar to the Hyperglycemia and Adverse Pregnancy Outcomes (HAPO) study. ${ }^{5}$ In the HAPO study, participants underwent a 2-hour, 75-g oral glucose tolerance test; glucose values were then compared with maternal and neonatal outcomes. An increasing 1-hour glucose value was associated with an increased risk of clinical neonatal hypoglycemia in the HAPO study. Although the rate of clinical neonatal hypoglycemia in the HAPO trial was $2.1 \%$, which is lower than this study, the trend was similar in both groups.

Our results concerning neonatal hypoglycemia must be interpreted with caution. Despite a difference in rates of neonatal hypoglycemia, there were no significant differences between NICU admissions between the groups, suggesting limited clinical consequences associated with this finding. Additionally, infants had to be tested prior to the neonate's first feeding 
and within 2 hours of birth, and therefore not all infants in the cohort were tested for neonatal hypoglycemia. However, routine postnatal care typically only tests neonatal glucose values for a clinical indication and it is recommended to continue this practice until further studies can be performed.

In regards to sample size, if the odds ratio for an adverse outcome associated with hypoglycemia (GLT < 90) was 2.0, and the proportion with the outcome in the group with GLT 90 to 119 was 0.20 , then the power is $84 \%$. However, our cohort may have been underpowered for less common outcomes or for more modestly increased odds ratios. Given this cohort was a secondary analysis of an observational cohort, enrollment was fixed and limited to primary study. Additionally, we acknowledge the majority of the cohort studied was Hispanic, and therefore these results may not be applicable or representative of the general population.

In summary, our study revealed that among women with a GLT $<120 \mathrm{mg} / \mathrm{dL}$ between 24 and 30 weeks of gestation, a result $<90 \mathrm{mg} / \mathrm{dL}$ is associated with a lower risk of neonatal hypoglycemia but not with any adverse maternal or neonatal outcomes. Future studies may determine whether even lower screening glucose values in women without diabetes have a greater impact on neonatal outcomes and possible long-term effects.

\section{Acknowledgments}

The project described was supported by grants from the Eunice Kennedy Shriver National Institute of Child Health and Human Development (HD27915, HD34116, HD40485, HD34208, HD27869, HD40500, HD40560, HD34136, HD40544, HD27860, HD40545, HD53097, HD21410, HD27917, HD40512, HD53118, HD36801), General Clinical Research Centers Grant (M01-RR00034), and the National Center for Research Resources (UL1RR024989, M01-RR00080, UL1-RR025764, C06-RR11234) and does not necessarily represent the official views of the Eunice Kennedy Shriver National Institute of Child Health and Human Development or the National Institutes of Health.

The authors thank the following Subcommittee members who participated in protocol development and coordination between clinical research centers (Francee Johnson, RN, BSN, and Jo-Ann Tillinghast, RN, MSN, Brown University), and protocol/data management and statistical analysis (Elizabeth Thom, $\mathrm{PhD}$ ).

In addition to the authors, other members of the Eunice Kennedy Shriver National Institute of Child Health and Human Development Maternal-Fetal Medicine Units Network are as follows:

Oregon Health \& Science University—J. Tolosa, L. Davis, E. Lairson, C. Cromett, C. Naze, M. Blaser

University of Texas Southwestern Medical Center-K.

Leveno, L. Moseley, J. Gold, D. Bradford, L. Fay, M. Garcia, F. Capellan

Columbia University-M. Miodovnik, F. Malone, S. Bous-leiman, H. Husami, V. Carmona, N. Fredericks, E. Gantioqui, B. Greenspan, M. Williams

University of Utah-K. Anderson, P. Ashby, and S. McAllister (University of Utah Health Sciences Center), S. Quinn and F. Castinella (LDS Hospital), A. Guzman and J. Steiner (McKay-Dee Hospital), J. Parker (Utah Valley Regional Medical Center)

University of Alabama at Birmingham—J. Sheppard, J. Tisdale, A. Northen, W. Andrews

Brown University—M. Carpenter, D. Catlow, D. Allard, M. Seebeck, J. Tillinghast

The Ohio State University—J. Iams, F. Johnson, C. Lat-imer, E. Weinandy, B. Maselli

University of North Carolina at Chapel Hill—K. Dorman, S. Brody, S. Timlin, J. Bernhardt 
Drexel University—M. Hoffman, E. Guzman, M. Talucci, T. Grossman, C. Perez, L. Zeghibe, P. Tabangin

Case Western Reserve University-MetroHealth Medical Center-B. Mercer, B. Stetzer, C. Milluzzi, W. Dalton, S. Pichette

Wake Forest University Health Sciences-M. Swain, P. Meis, J. White

The University of Texas Health Science Center at Houston—L. Gilstrap, K. Cannon, J. Martinez, D. Dusek

University of Texas Medical Branch—J. Moss, J. Brandon, A. Jackson, G. Hankins, D. Sharp

University of Pittsburgh-M. Bickus, H. Birkland, M. Cotroneo, N. Cuddy

Wayne State University—G. Norman, P. Lockhart, S. Blackwell, L. Quast

Northwestern University—P. Simon, G. Mallett

The George Washington University Biostatistics Center-E. Thom, J. Zachary, B. Getachew, C. Cobb, L. Leuchtenburg, S. Gilbert

Eunice Kennedy Shriver National Institute of Child Health and Human Development—S. Tolivaisa, K. Howell

\section{References}

1. Jovanovic L, Pettitt DJ. Gestational diabetes mellitus. JAMA. 2001; 286:2516-2518. [PubMed: 11722247]

2. Coustan, DR. Gestational diabetes. In: Harris, MI.; Cowie, CC.; Stern, MP.; Boyko, EJ.; Reiber, GE.; Bennett, PH., editors. Diabetes in America. 2. Baltimore, MD: National Institutes of Health; 1995. p. 703-717.

3. American College of Obstetricians and Gynecologists Committee on Practice Bulletins-Obstetrics. ACOG Practice Bulletin. Clinical management guidelines for obstetrician-gynecologists. Number 30, September 2001 (replaces Technical Bulletin Number 200, December 1994). Gestational diabetes Obstet Gynecol. 2001; 98:525-538.

4. Landon MB, Spong CY, Thom E, et al. Eunice Kennedy Shriver National Institute of Child Health and Human Development Maternal-Fetal Medicine Units Network. A multicenter, randomized trial of treatment for mild gestational diabetes. N Engl J Med. 2009; 361:1339-1348. [PubMed: 19797280]

5. Metzger BE, Lowe LP, Dyer AR, et al. HAPO Study Cooperative Research Group. Hyperglycemia and adverse pregnancy outcomes. N Engl J Med. 2008; 358:1991-2002. [PubMed: 18463375]

6. Kirwan JP, Hauguel-De Mouzon S, Lepercq J, et al. TNF-alpha is a predictor of insulin resistance in human pregnancy. Diabetes. 2002; 51:2207-2213. [PubMed: 12086951]

7. Catalano PM, Tyzbir ED, Wolfe RR, Roman NM, Amini SB, Sims EA. Longitudinal changes in basal hepatic glucose production and suppression during insulin infusion in normal pregnant women. Am J Obstet Gynecol. 1992; 167(4 Pt 1):913-919. [PubMed: 1415425]

8. Khouzami VA, Ginsburg DS, Daikoku NH, Johnson JW. The glucose tolerance test as a means of identifying intrauterine growth retardation. Am J Obstet Gynecol. 1981; 139:423-426. [PubMed: 7468709]

9. Langer O, Damus K, Maiman M, Divon M, Levy J, Bauman W. A link between relative hypoglycemia-hypoinsulinemia during oral glucose tolerance tests and intrauterine growth retardation. Am J Obstet Gynecol. 1986; 155:711-716. [PubMed: 3532796]

10. Piper JM, Field NT, Higby K, Elliott BD, Langer O. Maternal-fetal glucose metabolism and fetal growth retardation. Is there an association? J Reprod Med. 1996; 41:761-766. [PubMed: 8913979]

11. Weissman A, Solt I, Zloczower M, Jakobi P. Hypoglycemia during the 100-g oral glucose tolerance test: incidence and perinatal significance. Obstet Gynecol. 2005; 105:1424-1428. [PubMed: 15932839] 
12. Feinberg JH, Magann EF, Morrison JC, Holman JR, Polizzotto MJ. Does maternal hypoglycemia during screening glucose assessment identify a pregnancy at-risk for adverse perinatal outcome? $\mathrm{J}$ Perinatol. 2005; 25:509-513. [PubMed: 15908987]

13. Berkus MD, Langer O. Glucose tolerance test: degree of glucose abnormality correlates with neonatal outcome. Obstet Gynecol. 1993; 81:344-348. [PubMed: 8437783]

14. McLaughlin GB, Cheng YW, Caughey AB. Women with one elevated 3-hour glucose tolerance test value: are they at risk for adverse perinatal outcomes? Am J Obstet Gynecol. 2006; 194:e16e19. [PubMed: 16647890]

15. Cornblath M, Hawdon JM, Williams AF, et al. Controversies regarding definition of neonatal hypoglycemia: suggested operational thresholds. Pediatrics. 2000; 105:1141-1145. [PubMed: 10790476]

16. Alexander GR, Kogan MD, Himes JH. 1994-1996 U.S. singleton birth weight percentiles for gestational age by race, Hispanic origin, and gender. Matern Child Health J. 1999; 3:225-231. [PubMed: 10791363]

17. Gardosi J, Francis A. A customized standard to assess fetal growth in a US population. Am J Obstet Gynecol. 2009; 201:25, e1-e7. [PubMed: 19576371]

18. Bhutani VK, Johnson L, Sivieri EM. Predictive ability of a predischarge hour-specific serum bilirubin for subsequent significant hyperbilirubinemia in healthy term and near-term newborns. Pediatrics. 1999; 103:6-14. [PubMed: 9917432]

19. Agresti, A. Categorical Data Analysis. 1. New York, NY: Wiley Press; 1990. p. 100-102.

20. Limesand SW, Rozance PJ, Brown LD, Hay WW Jr. Effects of chronic hypoglycemia and euglycemic correction on lysine metabolism in fetal sheep. Am J Physiol Endocrinol Metab. 2009; 296:E879-E887. [PubMed: 19190258]

21. Stanley CA, Baker LS. The causes of neonatal hypoglycemia. N Engl J Med. 1999; 340:12001201. [PubMed: 10202173] 


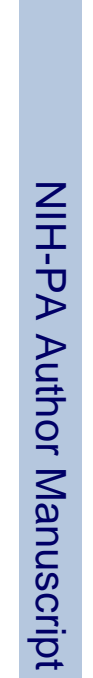

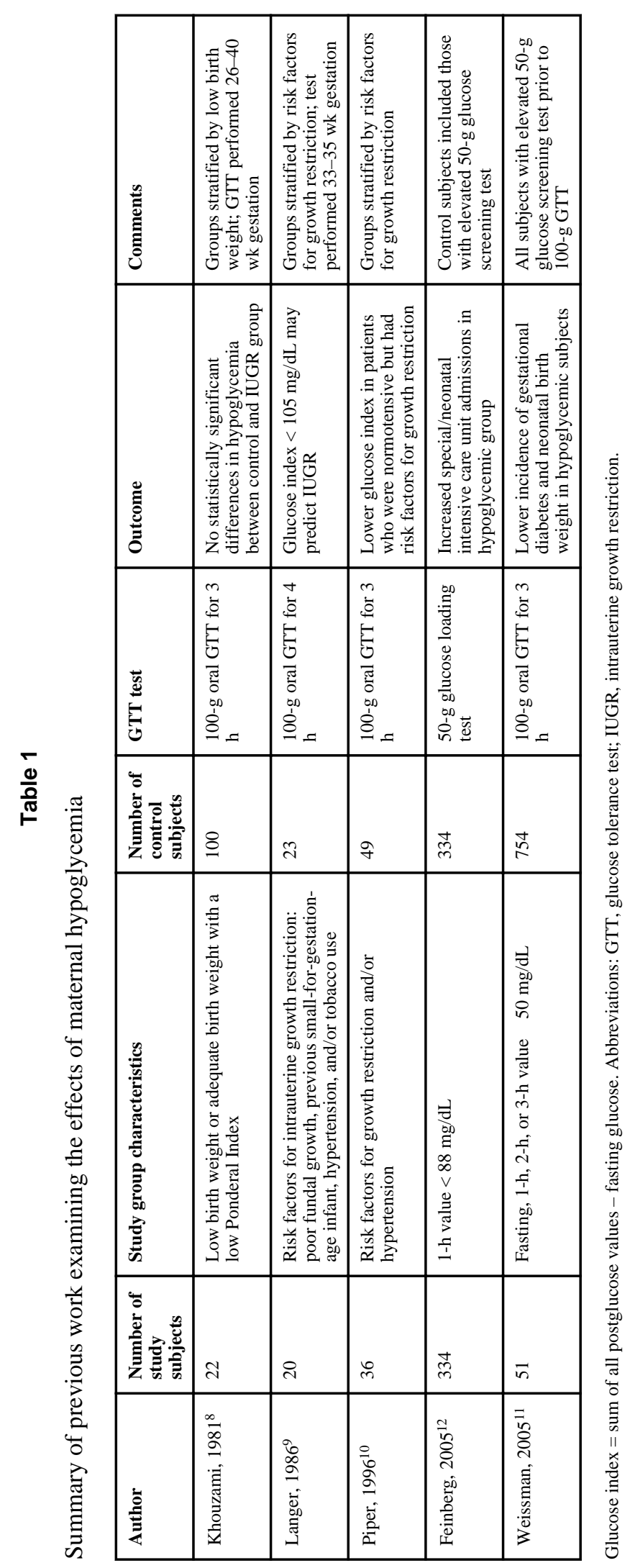

Am J Perinatol. Author manuscript; available in PMC 2014 May 15. 
Table 2

Characteristics by maternal GLT value

\begin{tabular}{|l|l|l|l|}
\hline Characteristics & GLT $<90$ mg/dL $(\boldsymbol{n}=\mathbf{1 3 9})$ & GLT 90-119 $\mathbf{~ g} / \mathbf{d L}(\boldsymbol{n}=\mathbf{2 9 7})$ & $\boldsymbol{p}$ Value \\
\hline Age, y (SD) & $25.4(5.5)$ & $25.0(5.3)$ & 0.47 \\
\hline Nulliparous, $n(\%)$ & $45(32.4)$ & $117(39.4)$ & 0.16 \\
\hline Race/ethnicity & & & 0.36 \\
\hline African-American, $n(\%)$ & $13(9.4)$ & $43(14.5)$ & \\
\hline Caucasian, $n(\%)$ & $41(29.5)$ & $77(25.9)$ & \\
\hline Hispanic, $n(\%)$ & $84(60.4)$ & $171(57.6)$ & \\
\hline Other, $n(\%)$ & $1(0.7)$ & $6(2.0)$ & \\
\hline Smoking, $n(\%)$ & $9(6.5)$ & $25(8.4)$ & 0.48 \\
\hline Alcohol use, $n(\%)$ & $3(2.2)$ & $10(3.4)$ & 0.76 \\
\hline BMI, prepregnancy & & & 0.11 \\
\hline$<18.5 \mathrm{~kg} / \mathrm{m}^{2}$ (underweight), $n(\%)$ & $1(0.8)$ & $7(2.5)$ & \\
\hline $18.5-24.9 \mathrm{~kg} / \mathrm{m}^{2}, n(\%)$ & $64(49.2)$ & $131(47.5)$ & \\
\hline $25-29.9 \mathrm{~kg} / \mathrm{m}^{2}$ (overweight), $n(\%)$ & $47(36.2)$ & $75(27.2)$ & \\
\hline $30-39.9 \mathrm{~kg} / \mathrm{m}^{2}$ (obesity), $n(\%)$ & $16(12.3)$ & $54(19.6)$ & \\
\hline$\geq 40 \mathrm{~kg} / \mathrm{m}^{2}$ (morbid obesity), $n(\%)$ & $2(1.5)$ & $9(3.3)$ & 0.0001 \\
\hline GLT value, $\mathrm{mg} / \mathrm{dL}$ (SD) & $78.9(8.4)$ & $105.8(8.5)$ & \\
\hline
\end{tabular}

Abbreviations: BMI, body mass index; GLT, glucose loading test; SD, standard deviation. 
Table 3

Maternal outcomes by GLT value

\begin{tabular}{|l|l|l|l|}
\hline Outcome & GLT $<$ 90 mg/dL & GLT 90-119 mg/dL & $p$ Value \\
\hline Weight gain, $\mathrm{kg}(\mathrm{SD})$ & $5.05(5.0)$ & $5.08(3.6)$ & 0.69 \\
\hline Spontaneous labor, $n(\%)$ & $63(47.4)$ & $116(40.1)$ & 0.16 \\
\hline Cesarean delivery, $n(\%)$ & $32(24.1)$ & $72(24.9)$ & 0.85 \\
\hline Gestational hypertension/preeclampsia, $n(\%)$ & $6(4.5)$ & $24(8.3)$ & 0.16 \\
\hline Abruption, $n(\%)$ & $1(0.75)$ & $4(1.4)$ & $>0.99^{a}$ \\
\hline
\end{tabular}

Abbreviation: GLT, glucose loading test; SD, standard deviation.

$a_{\text {Fisher exact two-sided test. }}$ 
Table 4

Neonatal outcomes by GLT value

\begin{tabular}{|l|l|l|l|}
\hline Outcome & GLT $<$ 90 mg/dL & GLT 90-119 mg/dL & $\boldsymbol{p}$ Value \\
\hline Gestational age at delivery, wk (SD) & $39.5(1.4)$ & $39.3(1.6)$ & 0.68 \\
\hline Birth weight, g (SD) & $3352(469)$ & $3332(459)$ & 0.94 \\
\hline Birth weight percentile $a$ & $50.32 \pm 9.2$ & $49.4 \pm 8.5$ & 0.76 \\
\hline Large for gestational age, $n(\%)$ & $11(8.3)$ & $17(5.9)$ & 0.36 \\
\hline Small for gestational age, $n(\%)$ & $12(9.0)$ & $14(4.8)$ & 0.10 \\
\hline Ponderal index (SD) & $2.71(0.25)$ & $3.02(3.34)$ & 0.97 \\
\hline NICU admissions, $n(\%)$ & $13(9.8)$ & $16(5.5)$ & 0.11 \\
\hline Neonatal hypoglycemia, $n(\%)$ & $6(5.7)$ & $38(16.5)$ & 0.006 \\
\hline Neonatal hyperbilirubinemia, $n(\%)$ & $13(10.8)$ & $26(9.4)$ & 0.66 \\
\hline
\end{tabular}

Abbreviations: NICU, neonatal intensive care unit; SD, standard deviation.

${ }^{a}$ Gardosi J, Francis A. A customized standard to assess fetal growth in a US population. Am J Obstet Gynecol 2009;201:25.e1-7. 17 
Table 5

Neonatal hypoglycemia stratified by GLT value ${ }^{a}$

\begin{tabular}{|l|l|l|l|}
\hline GLT Value (mg/dL) & Patients (n) & Cases & Rate of Neonatal Hypoglycemia (\%) \\
\hline$<80$ & 50 & 3 & 6.0 \\
\hline $80-89$ & 56 & 3 & 5.4 \\
\hline $90-99$ & 65 & 9 & 13.9 \\
\hline $100-109$ & 84 & 13 & 15.5 \\
\hline $110-119$ & 82 & 16 & 19.5 \\
\hline
\end{tabular}

$p=0.011$, test for trend. Abbreviations: GLT, glucose loading test.

${ }^{a}$ Ninety-nine neonates did not have neonatal glucose levels measured. 
Table 6

Neonatal hyperbilirubinemia stratified by GLT value ${ }^{a}$

\begin{tabular}{|l|l|l|l|}
\hline GLT value $(\mathbf{m g} / \mathbf{d L})$ & Patients $(\boldsymbol{n})$ & Cases & Rate of neonatal hyperbilirubinemia $(\%)$ \\
\hline$<80$ & 53 & 4 & 7.5 \\
\hline $80-89$ & 67 & 9 & 13.4 \\
\hline $90-99$ & 75 & 2 & 2.7 \\
\hline $100-109$ & 103 & 11 & 10.7 \\
\hline $110-119$ & 98 & 13 & 13.3 \\
\hline
\end{tabular}

$p=0.38$, test for trend. Abbreviations: GLT, glucose loading test.

${ }^{a}$ Forty neonates did not have neonatal bilirubin levels measured. 